\title{
Monitoring and anxiety disorders symptoms in children
}

Citation for published version (APA):

Muris, P. E. H. M., Merckelbach, H. L. G. J., Gadet, B. P. M. T., \& Meesters, C. M. G. (2000). Monitoring and anxiety disorders symptoms in children. Personality and Individual Differences, 29(4), 775-781. https://doi.org/10.1016/S0191-8869(99)00223-8

Document status and date:

Published: 01/01/2000

DOI:

10.1016/S0191-8869(99)00223-8

Document Version:

Publisher's PDF, also known as Version of record

\section{Please check the document version of this publication:}

- A submitted manuscript is the version of the article upon submission and before peer-review. There can be important differences between the submitted version and the official published version of record.

People interested in the research are advised to contact the author for the final version of the publication, or visit the DOI to the publisher's website.

- The final author version and the galley proof are versions of the publication after peer review.

- The final published version features the final layout of the paper including the volume, issue and page numbers.

Link to publication

\footnotetext{
General rights rights.

- You may freely distribute the URL identifying the publication in the public portal. please follow below link for the End User Agreement:

www.umlib.nl/taverne-license

Take down policy

If you believe that this document breaches copyright please contact us at:

repository@maastrichtuniversity.nl

providing details and we will investigate your claim.
}

Copyright and moral rights for the publications made accessible in the public portal are retained by the authors and/or other copyright owners and it is a condition of accessing publications that users recognise and abide by the legal requirements associated with these

- Users may download and print one copy of any publication from the public portal for the purpose of private study or research.

- You may not further distribute the material or use it for any profit-making activity or commercial gain

If the publication is distributed under the terms of Article $25 \mathrm{fa}$ of the Dutch Copyright Act, indicated by the "Taverne" license above, 


\title{
Monitoring and anxiety disorders symptoms in children
}

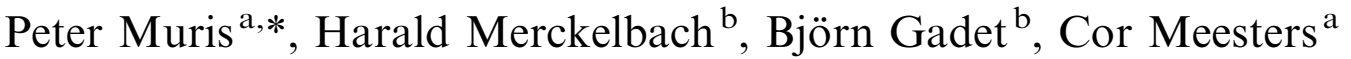 \\ ${ }^{a}$ Department of Medical, Clinical and Experimental Psychology, Maastricht University, P.O. Box 616, 6200 MD \\ Maastricht, Netherlands \\ ${ }^{\mathrm{b}}$ Department of Psychology, Maastricht University, P.O. Box 616, 6200 MD Maastricht, Netherlands
}

Received 21 May 1999; received in revised form 17 August 1999; accepted 1 October 1999

\begin{abstract}
The current study investigated the relationship between the monitoring coping style and anxiety disorder symptoms in children. Primary school children $(N=117)$ aged between 8 and 12 years completed the Monitoring and Blunting Scale for Children (MBSC), an instrument that intends to measure monitoring coping style and the Screen for Child Anxiety Related Emotional Disorders (SCARED), an instrument that measures anxiety disorder symptoms of children. Children who strongly relied on a high monitoring coping style displayed higher levels of anxiety disorder symptoms compared to other children. This result is in agreement with previous research showing adverse effects of the monitoring coping style. (C) 2000 Elsevier Science Ltd. All rights reserved.
\end{abstract}

Keywords: Monitoring coping style; Anxiety disorders symptoms; Children

\section{Introduction}

Monitoring refers to the extent to which an individual scans for or attends to threatening information. It is thought to represent an important index of individual differences in response to aversive stimuli or situations (see Miller, Combs \& Kruus, 1993). A number of studies have examined whether monitoring plays a role in how people cope with threatening situations. A consistent finding in these studies is that high monitors (i.e. individuals who strongly rely on a monitoring coping style) react with more distress and physical and psychological dysfunctions

\footnotetext{
* Corresponding author. Tel.: +31-43-388-1264; fax: +31-43-367-0968.

E-mail address: p.muris@dep.unimaas.nl (P. Muris).
} 
to stressful events than do low monitors (i.e. individuals who do not habitually rely on a monitoring coping style) (see for a review, Miller et al., 1993).

In an attempt to conceptualize the disruptive effects of monitoring, Miller (e.g. Miller, Roussi, Caputo \& Kruus, 1995) formulated the monitoring process model. According to this model, high and low monitors differ in their encoding of threatening situations. That is, high, but not low monitors are more inclined to scan for internal and external threat cues and access them readily. This process would promote intrusive ideation. In addition, high monitors would tend to interpret neutral or ambiguous information in a threatening way, which would result in exaggerated perceptions of personal risk. A high frequency of intrusive ideation and an exaggerated sense of risk would lead to heightened anxiety and distress.

Some authors have proposed that monitoring might be involved in the development of anxiety disorder symptoms. In Miller's (1992; p. 266) words: "It is tempting to speculate that individuals who are disposed to monitor for cues of danger when they are under threat may be more vulnerable to the development of these disorders". In various anxiety disorders, cognitive aberrations occur that bear strong resemblance to monitoring. For example, patients with generalized anxiety disorder are hypervigilant to potential danger and threat. They tend to worry excessively, even about fairly trivial aspects of their lives. In a similar vein, panic disorder patients attend intently to their bodily symptoms and interpret them in a catastrophic way. Furthermore, patients with post-traumatic stress disorder are plagued by high levels of intrusive thoughts about the traumatic incident. Finally, phobic patients frequently scan their environment for phobia-related stimuli. Thus, it is conceivable that a habitual reliance on a monitoring coping style is linked to the cognitive aberrations that typically accompany anxiety disorder symptoms (see, for a brief discussion, Muris, de Jongh, Van Zuuren \& Schoenmakers, 1996a).

Hoffner (1993) noted that monitoring coping strategies may also be found in children. In her study, children aged between 6 and 12 years were asked to imagine four uncontrollable threatening situations. Next, they were interviewed about what they would do or think about while being in that situation. It appeared that across all age levels, there were children who reported monitoring coping responses. The most frequently mentioned monitoring responses were "mentally focusing on aspects of the threat", "information seeking" and "attention to threat cues". Interestingly, Miller et al. (1995) investigated the effects of dispositional monitoring (as determined by a self-report questionnaire) in 7-12-year-old children who had to undergo invasive dental treatment. Results were consistent with adult studies on monitoring. That is, children who were high monitors reacted with more distress and anxiety than children who were low monitors. So far, only one study directly examined the relationship between monitoring and anxiety symptoms in children. In that study, Muris, Meesters and Merckelbach (1996b) had normal primary school children complete a measure of dispositional monitoring and the revised version of the Fear Survey Schedule for Children (FSSC-R; Ollendick, 1983). It was found that children who were high monitors reported more fears than children who were low monitors.

The current study further investigated the connection between monitoring and anxiety symptoms in children. To examine this issue, a sample of children aged between 8 and 12 years were asked to complete the Monitoring and Blunting Scale for Children (MBSC; Kliewer, 1991), an instrument that purports to measure a monitoring coping style. Children also 
completed the revised version of the Screen for Child Anxiety Related Emotional Disorders (SCARED; Birmaher et al., 1997; Muris, Merckelbach, Schmidt \& Mayer, 1999), a self-report questionnaire that measures symptoms of $D S M-I V$ defined anxiety disorders in children. As trait anxiety is considered to be an important vulnerability factor for anxiety symptoms (e.g. Eysenck, 1992), children were also asked to fill out the trait version of the Spielberger (1973) State-Trait Anxiety Inventory for Children (STAIC). This was done in order to examine the association between monitoring and anxiety disorder symptoms while partialling out the contribution of trait anxiety.

\section{Method}

\subsection{Children and procedure}

The sample consisted of 117 primary school children (41 boys and 76 girls) aged between 8 and 12 years $(M=10.5$, S.D. $=1.2)$.

\subsection{Questionnaires}

The Monitoring and Blunting Scale for Children (MBSC; Kliewer, 1991; Dutch translation by Bijttebier, 1998) is intended to measure monitoring and blunting (distracting) coping dispositions in children. The MBSC is a 56-item questionnaire consisting of 4 threatening scenarios (a vaccination by the doctor, a roller coaster that has broken down, a bad report card and a storm at school). Each scenario is followed by 14 separate coping responses. Half of the responses listed are monitoring responses, while the other half refer to blunting responses. For example, in the vaccination scenario, an illustrative monitoring response is "ask the doctor what exactly he is going to do", whereas "try to think about happy things while I get the shot" is a typical blunting option. Children have to indicate which of the 14 coping options they would choose if they were actually confronted with the scenario; they can choose as many or as few options as they like. Responses are summed across all scenarios to yield total monitoring and total blunting scores (range 0-28). Given the present study's emphasis on monitoring, blunting scores were not included in the data analyses.

The Screen for Child Anxiety Related Emotional Disorders (SCARED; Birmaher et al., 1997; Muris et al., 1999) contains 66 items that can be allocated to nine separate DSM-IV (American Psychiatric Association, 1994) linked subscales: panic disorder, separation anxiety disorder, generalized anxiety disorder, social phobia, obsessive-compulsive disorder, traumatic stress disorder and three types of specific phobias (animal phobia, blood-injection-injury phobia and situational-environmental phobia). Children are asked to rate how frequently they experience each symptom using a 3-point scale (i.e. $0=$ almost never, $1=$ sometimes and $2=$ often). SCARED total and subscale scores are derived by summing relevant items.

The trait version of the State-Trait Anxiety Inventory for Children (STAIC; Spielberger, 1973) contains 20 items that have to be rated on a 3-point scale: $1=$ almost never, $2=$ sometimes or $3=$ often. STAIC scores range between 20 and 60 with higher scores reflecting higher levels of trait anxiety. 


\section{Results and discussion}

Before addressing the main research questions of the present study, some general statistics are presented. To begin with, all questionnaires were reliable in terms of internal consistency. Cronbach's $\alpha$ s were 0.84 for MBSC monitoring, 0.91 for STAIC trait anxiety and 0.95 for the SCARED total score. As for the separate SCARED subscales, $\alpha$ s varied between 0.63 (social phobia) and 0.84 (panic disorder). Furthermore, significant gender differences were found for MBSC monitoring and various SCARED scales. As can be seen in Table 1, girls had higher monitoring scores and reported higher levels of anxiety disorder symptoms than boys.

Trait anxiety was significantly related to anxiety disorder symptoms: the correlation (corrected for gender) between STAIC and SCARED total score was 0.92, $p<0.001$. As well, MBSC monitoring appeared to be significantly associated with trait anxiety: $r=0.34, p<$ 0.001. Most importantly, MBSC monitoring correlated positively with anxiety disorder symptomatology as indexed by the SCARED total score $(r=0.38, p<0.001)$. Thus, the more children relied on a monitoring coping style, the higher their level of anxiety disorder symptoms. Even when levels of trait anxiety were held constant, the partial correlation between MBSC monitoring and SCARED anxiety disorder symptoms reached significance: $r=0.19, p$ $<0.05$.

The link between MBSC monitoring and anxiety disorder symptoms was further analyzed by dividing the sample into high and low monitors. This was done by means of a split-half procedure performed on MBSC monitoring scores of boys and girls separately. Next, SCARED scores were subjected to a 2 (groups: high vs. low monitors) $\times 2$ (gender) analysis of variance (ANOVA). Not only a main effect of gender $(F(1,113)=5.5, p<0.05)$ was found but also a significant effect of group $(F(1,113)=9.0, p<0.005)$. As can be seen in Table 2,

Table 1

Main statistics (mean, standard deviation, gender difference and Cronbach's $\alpha$ ) for the various measures ${ }^{\mathrm{a}}$

\begin{tabular}{lllll}
\hline & Total group $(N=117)$ & Boys $(n=41)$ & Girls $(n=76)$ & $\alpha$ \\
\hline MBSC monitoring & $14.4(5.7)$ & $11.8(6.2)$ & $15.8(5.0)^{*}$ & 0.84 \\
STAIC trait anxiety & $32.2(8.4)$ & $30.5(7.9)$ & $33.2(8.6)$ & 0.91 \\
SCARED & & & & \\
Total score & $35.6(22.0)$ & $29.0(20.3)$ & $39.2(22.2)^{*}$ & 0.95 \\
Panic disorder & $5.6(4.6)$ & $4.7(4.4)$ & $6.1(4.7)$ & 0.84 \\
Generalized anxiety disorder & $5.4(4.0)$ & $4.4(3.6)$ & $5.9(4.1)^{*}$ & 0.83 \\
Social phobia & $2.9(1.9)$ & $2.4(1.6)$ & $3.2(2.0)^{*}$ & 0.63 \\
Separation anxiety disorder & $6.1(4.4)$ & $5.3(4.4)$ & $6.6(4.4)$ & 0.80 \\
Obsessive-compulsive disorder & $5.3(3.6)$ & $4.9(3.7)$ & $5.5(3.5)$ & 0.73 \\
Traumatic stress disorder & $3.0(2.5)$ & $2.3(2.3)$ & $3.4(2.4)^{*}$ & 0.81 \\
Animal phobia & $0.9(1.5)$ & $0.7(1.2)$ & $1.1(1.6)$ & 0.81 \\
Blood-injection-injury phobia & $3.6(3.0)$ & $2.3(2.0)$ & $4.3(3.2)^{*}$ & 0.71 \\
Situational-environmental phobia & $2.7(2.5)$ & $2.0(2.1)$ & $3.1(2.6)^{*}$ & 0.72 \\
\hline
\end{tabular}

\footnotetext{
${ }^{\mathrm{a}} \mathrm{MBSC}=$ Monitoring and Blunting Scale for Children; STAIC = State-Trait Anxiety Inventory for Children; SCARED $=$ Screen for Child Anxiety Related Emotional Disorders. ${ }^{*}$ Gender difference significant at $p<0.05$.
} 
Table 2

Mean SCARED scores (standard deviations) for high and low monitors ${ }^{\mathrm{a}}$

\begin{tabular}{|c|c|c|c|c|c|c|c|c|}
\hline \multirow[t]{2}{*}{ SCARED } & \multicolumn{3}{|c|}{ High monitors $(n=58)$} & \multicolumn{3}{|c|}{ Low monitors $(n=59)$} & \multirow[t]{2}{*}{$F$ (group) } & \multirow[t]{2}{*}{$P$} \\
\hline & total group & boys $(n=19)$ & girls $(n=39)$ & total group & boys $(n=22)$ & girls $(n=37)$ & & \\
\hline Total score & $41.4(23.0)$ & $37.7(22.5)$ & $43.2(23.3)$ & $29.9(19.6)$ & $21.4(14.9)$ & $35.0(20.5)$ & 9.0 & $<0.005$ \\
\hline Panic disorder & $7.0(5.1)$ & $6.1(5.2)$ & $7.4(5.1)$ & $4.2(3.6)$ & $3.4(3.1)$ & $4.7(3.8)$ & 10.0 & $<0.005$ \\
\hline Generalized anxiety disorder & $6.1(3.9)$ & $5.4(4.2)$ & $6.5(3.7)$ & $4.7(4.0)$ & $3.5(2.6)$ & $5.4(4.5)$ & 3.9 & $<0.05$ \\
\hline Social phobia & $3.3(1.9)$ & $3.1(1.4)$ & $3.4(2.1)$ & $2.5(1.8)$ & $1.9(1.7)$ & $2.9(1.7)$ & 6.4 & $<0.05$ \\
\hline Separation anxiety disorder & $6.9(4.8)$ & $6.6(5.0)$ & $7.1(4.8)$ & $5.3(3.9)$ & $4.2(3.5)$ & $6.0(3.9)$ & 4.5 & $<0.05$ \\
\hline Obsessive-compulsive disorder & $6.2(3.8)$ & $6.5(4.0)$ & $6.0(3.8)$ & $4.4(3.1)$ & $3.5(2.9)$ & $5.0(3.2)$ & 9.1 & $<0.005$ \\
\hline Traumatic stress disorder & $3.3(2.5)$ & $3.1(2.8)$ & $3.4(2.4)$ & $2.7(2.4)$ & $1.5(1.6)$ & $3.5(2.5)$ & 2.7 & $<0.10$ \\
\hline Animal phobia & $1.1(1.7)$ & $1.2(1.4)$ & $1.0(1.9)$ & $0.8(1.3)$ & $0.3(0.9)$ & $1.1(1.4)$ & 2.1 & NS \\
\hline Blood-injection-injury phobia & $4.3(3.0)$ & $2.9(2.2)$ & $5.0(3.2)$ & $2.9(2.7)$ & $1.9(1.8)$ & $3.5(3.0)$ & 5.8 & $<0.05$ \\
\hline Situational-environmental phobia & $3.1(2.5)$ & $2.8(2.5)$ & $3.2(2.6)$ & $2.4(2.4)$ & $1.3(1.4)$ & $3.0(2.7)$ & 3.4 & $<0.10$ \\
\hline
\end{tabular}

${ }^{\text {a }}$ SCARED $=$ Screen for Child Anxiety Related Emotional Disorders. 
high monitors displayed higher levels of anxiety disorder symptoms than low monitors, mean SCARED total scores being 41.4 (S.D. = 23.0) vs. 29.9 (S.D. = 19.6), respectively. Additional ANOVAs indicated that this group effect was evident for most SCARED subscales (see Table 2).

In conclusion, then, the present study found a moderate but significant correlation between monitoring and anxiety disorder symptoms in normal children. When controlling for levels of trait anxiety, this correlation attenuated but remained significant. Further analysis showed that monitoring was associated with a broad range of anxiety disorder symptoms. Altogether, these findings support Miller's (1992) suggestion that a monitoring coping style might be involved in a broad range of anxiety symptoms. However, it is important to note that the current study suffers from several limitations. First, the study relied on a sample of nonreferred children. Replication of the present findings in anxiety disordered samples is certainly needed. Second, the present study was correlational in nature and hence does not allow for causal interpretations of the link between monitoring and anxiety symptoms. For example, it is possible that (high) monitoring merely is a manifestation of anxious individuals' attentional bias for threatening material (see Davey, Hampton, Farrell \& Davidson, 1992). Otherwise, it may well be that monitoring actually is a risk factor for developing anxiety disorders. In that case, it would be important to examine why high monitors display higher levels of anxiety disorder symptoms. According to the monitoring process model, several possibilities suggest themselves. High monitors may either perceive more risk or may display higher levels of intrusive and worrisome thinking. Clearly, these issues warrant further research.

\section{Acknowledgements}

Children, teachers and staff of primary school 'De Kring' in Maastricht, The Netherlands, are thanked for their participation in the present study. Patricia Bijttebier is acknowledged for providing the Dutch translation of the Monitoring and Blunting Scale for Children.

\section{References}

American Psychiatric Association (1994). Diagnostic and statistical manual of mental disorders (DSM-IV) (4th ed.). Washington, DC: American Psychiatric Association.

Bijttebier, P. (1998). Monitoring and blunting coping styles in children. Leuven, Belgium: Katholieke Universiteit Leuven, Faculteit Psychologie en Pedagogische Wetenschappen.

Birmaher, B., Khetarpal, S., Brent, D., Cully, M., Balach, L., Kaufman, J., \& McKenzie Neer, S. (1997). The Screen for Child Anxiety Related Emotional Disorders (SCARED): scale construction and psychometric characteristics. Journal of the American Academy of Child and Adolescent Psychiatry, 36, 545-553.

Eysenck, M. W. (1992). Anxiety: the cognitive perspective. Hove: Lawrence Erlbaum.

Davey, G. C. L., Hampton, J., Farrell, J., \& Davidson, S. (1992). Some characteristics of worrying: evidence for worrying and anxiety as separate constructs. Personality and Individual Differences, 13, 133-147.

Hoffner, C. (1993). Children's strategies for coping with stress: monitoring and blunting. Motivation and Emotion, 17, 91-106.

Kliewer, W. (1991). Coping in middle childhood: relations to competence, type A behavior, monitoring, blunting and locus of control. Developmental Psychology, 27, 689-697. 
Miller, S. M. (1992). Monitoring and blunting in the face of threat: implications for adaptation and health. In L. Montada, S. H. Filipp, \& M. J. Lerner, Life crisis and experiences of loss in adulthood (pp. 255-273). Hillside: Erlbaum.

Miller, S. M., Combs, C., \& Kruus, L. (1993). Tuning in and tuning out: confronting the effects of confrontation. In H. W. Krohne, Attention and avoidance: strategies in coping with aversiveness (pp. 51-69). Göttingen: Hogrefe \& Huber.

Miller, S. M., Roussi, P., Caputo, C., \& Kruus, L. (1995). Patterns of children's coping with an aversive dental treatment. Health Psychology, 14, 236-246.

Muris, P., De Jongh, A., Van Zuuren, F. J., \& Schoenmakers, N. (1996a). Monitoring-blunting coping styles and cognitive symptoms of dental fear. European Journal of Psychology, 10, 35-44.

Muris, P., Meesters, C., \& Merckelbach, H. (1996b). Monitoring and fearfulness in children. Personality and Individual Differences, 21, 1059-1061.

Muris, P., Merckelbach, H., Schmidt, H., \& Mayer, B. (1999). The revised version of the Screen for Child Anxiety Related Emotional Disorders (SCARED-R): factor structure in normal children. Personality and Individual Differences, 26, 99-112.

Ollendick, T. H. (1983). Reliability and validity of the revised Fear Survey Schedule for Children (FSSC-R). Behaviour Research and Therapy, 21, 685-692.

Spielberger, C. D. (1973). Manual for the State-Trait Anxiety Inventory for Children. Palo Alto, CA: Consulting Psychologists Press. 